\title{
SOLVING THE LABORATORY DILEMMA IN DISTANCE LEARNING GENERAL CHEMISTRY
}

\author{
Dr. Jimmy Reeves \\ University of North Carolina at Wilmington \\ 601 S. College Rd. \\ Wilmington, NC 28403 \\ Email: reeves@uncw.edu \\ Dr. Doris Kimbrough \\ University of Colorado at Denver \\ Chemistry Department \\ Campus Box 194 \\ P.O. Box 173364 \\ Denver, CO 80204 \\ Email: doris.kimbrough@cudenver.edu
}

\begin{abstract}
Making a laboratory science course accessible to distance learners requires eliminating certain barriers. This paper describes one semester introductory chemistry courses for science and non-science majors that feature laboratory experiments that students can do at home, using materials readily available from local grocery and hardware stores. Courses using this approach have been offered successfully for several years at the University of Colorado at Denver, Cape Fear Community College and the University of North Carolina at Wilmington, and the laboratory experiences of the distance learners compares favorably with that of traditional students. This paper describes the important features of the distance learning courses, and provides assessment results that indicate the suitability of these experiments as replacement for traditional laboratories.
\end{abstract}

\section{KEY WORDS}

Kitchen chemistry, Online laboratories, General chemistry

\section{INTRODUCTION}

It is an especially difficult challenge to offer a distance learning course in a laboratory science, but this challenge must be met if undergraduate degree programs for distance learners are to be successful. Among the basic studies requirements of most universities is the completion of at least one laboratory science course, and all health related majors require at least one semester of laboratory-based general chemistry. One possibility is to require distance learners to come to campus once a week to perform the laboratories, but this severely limits the flexibility and scope of the course. A second is to replace laboratories with virtual experiments, but these are often unrealistic and do not expose the students to the sights, sounds and conditions that make chemistry an experimental science. This paper describes a third alternative, doing chemistry experiments in the students' kitchens. 
Properly designed kitchen chemistry experiments address the problems with the other choices. Because they use materials readily available at grocery and hardware stores, and involve techniques no more dangerous than boiling water, the experiments don't require specialized laboratory facilities or close supervision by a trained laboratory instructor. Because they involve making measurements on real chemicals found in the home, they bring the sights, sounds and conditions of experimental science to the place where students do most of their real life chemistry, their kitchens. Nevertheless, a prevailing concern about these types of experiments is that they lack the precision and rigor of traditional experiments, and fail to expose students to the specialized equipment used in modern chemistry laboratories.

Despite these concerns, we developed a series of home-based experiments for first semester general chemistry courses for both science and non-science majors after receiving funding from the Learning Anytime Anywhere Partnership (LAAP) program administered by the US Department of Education through its Funds for the Improvement of Secondary Education (FIPSE) program. The resulting experiments have been utilized in general chemistry courses for non-science majors at the University of Colorado at Denver, and for science majors at Cape Fear Community College (CFCC) and the University of North Carolina at Wilmington (UNCW). The experiments for science majors have also been assessed to determine their suitability as substitutes for those done traditional laboratories. This paper discusses design of the course and the assessments that have been carried out.

\section{DESIGN AND ASSESSMENT OF THE “LECTURE” PORTION OF THE DISTANCE LEARNING COURSE}

Distance learning general chemistry has been taught successfully at Cape Fear Community College for nearly four years. Designed to parallel the general chemistry course for science majors offered at the University of North Carolina at Wilmington (CHM 101), the CFCC course provides the same teaching materials and follows the same schedule as the UNCW course. The distance learning students also take the same exams as the UNCW students, but they do specially designed laboratories at home in their kitchens. The articulation agreement between CFCC and UNCW ensures that this course will transfer to UNCW as CHM 101, the first semester introductory chemistry course for science majors.

The distance learning courses features a website that includes a calendar with links to outlines and course notes (http://aa.uncw.edu/reeves/chm101/cfcc/calendar.htm). While the students are not required to complete any single assignment on a given day, they are expected to complete the week's assignments on a regular basis, and are given web-based weekly quizzes and homework assignments that are graded. They have access to the instructor by email, phone, or in person, if they come to the campus.

Summative assessment tools for both the distance learning course and the traditional course taught at UNCW included online quizzes and homework (15\%), three hourly exams (50\%), formal lab reports (15\%) and a final exam (20\%). The final was comprehensive, and students were given the opportunity to replace exam scores if they achieved higher scores on the portions of the final exam that covered the same material. Using this approach, the final exam represented the minimum achievement for $70 \%$ of the course content (the exams), and was an excellent tool by which to compare the performance of the traditional and distance learning students in the lecture portion of the course. As displayed in figure 1, distance learners compared very favorably to their traditional counterparts, and the high school students performed exceptionally well. 


\section{Distribution of Final Exam Grades in Gen Chem}

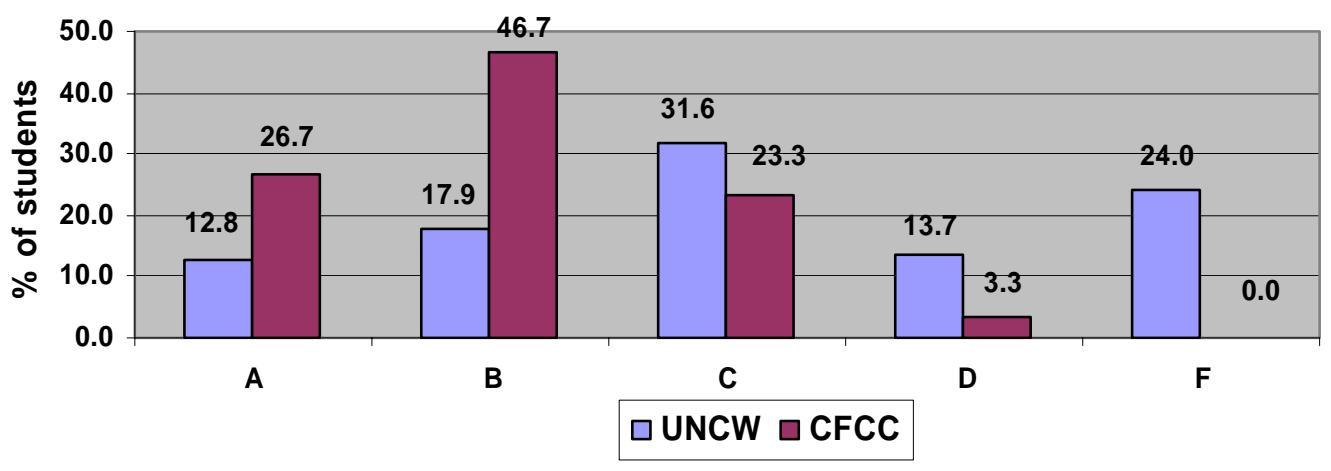

Figure 1: Distribution of Final Exam Grades for traditional (blue) and distance learning community college (purple) students

\section{DESIGN AND ASSESSMENT OF THE “LABORATORY” PORTION OF THE DISTANCE LEARNING COURSE}

The laboratory portion of the distance learning course is composed of nine experiments that are designed to be carried out by individuals in their kitchens. The experiments provide hands-on demonstrations of chemical principles, and are closely modeled after those done in the traditional CHM 101 laboratory program at UNCW. The kitchen chemistry experiments are available on the World Wide Web (http://aa.uncw.edu/reeves/OnLineLabs/Index.html), and feature interactive questions for both the introduction and discussion portions, as well as videos of important lab procedures and complete lists of all materials needed to carry out each experiment. With the exception of an inexpensive balance, the students can purchase everything they need from local grocery or hardware stores, and all materials are non-toxic and environmentally friendly (green). The laboratories are quantitative and each requires a formal lab reports that incorporates Microsoft Excel and Word.

Two approaches were taken to assess the validity of substituting kitchen chemistry experiments for the traditional laboratory experience. First, a checklist of learning objectives that summarizes the general and specific skills that general chemistry students at UNCW encounter in the traditional laboratory was compared to one derived from the kitchen chemistry laboratories. The distance learning students were exposed to 9 of the17 objectives to which UNCW students were exposed, while the distance learners completed 7 additional learning objectives not available to the traditional students. These differences were primarily due to variations in the experiments carried out by the two groups, and are typical of those found among traditional laboratory courses at different institutions.

For the second approach, three laboratory practicals, Qualitative Analysis, Paper Chromatography and Density, were developed and administered to groups of traditional (UNCW) and distance learning (CFCC) students. Each of five laboratory sections of the traditional students did one of these exercises during their normal laboratory period, while every distance learning student did all three on a designated Saturday morning in the laboratory facilities at CFCC. Areas of evaluation included Lab Procedure, Data Presentation, and Data Analysis/Conclusions. The procedures were scored by multiple observers using identical checklists, while the presentation and analysis sections were scored from the hard-copies submitted by the students. As indicated in figure 2, the distance learning students who had carried out the kitchen chemistry labs outperformed their UNCW counterparts in all three areas. 




Figure 2: Comparison of Laboratory Practical Results for Traditional (UNCW) and Distance Learning (CFCC) Students.

Of particular interest is the fact that, as evidenced by the results of the procedural evaluation, distance learning students were at least as competent as their traditional counterparts in utilizing laboratory equipment such as beakers, graduated cylinders and electronic balances, despite the fact that this type of equipment was not available to them in their kitchens. It appears that in the case of the first semester introductory chemistry course, the laboratory goals can be achieved equally well by the distance learners doing the Kitchen Chemistry Laboratories at home as they can by students in traditional laboratories.

\section{FACTORS THAT CONTRIBUTED TO THE SUCCESS OF THE DISTANCE LEARNING COURSE}

The students in the distance learning courses have indicated that the most important features that led to their success were its well-organized calendar that included links to all lessons, assignments, laboratories and quizzes, and the course instructor's accessibility and commitment to their success. They also said that they found that the Kitchen Chemistry experiments enhanced their appreciation of the relevance of chemistry in their lives because they involved familiar materials and measurements done in familiar surroundings. The instructor indicated that weekly quizzes and homework assignments were instrumental in keeping students on-task, and that the formal laboratory reports helped them clarify the reasons the experiments were being performed and promoted their understanding of the topics that were addressed.

\section{FUTURE GOALS FOR THE DISTANCE LEARNING COURSE}

Three additional experiments exploring the topics of acids and bases, emission of light by excited atoms and molecules and identification of an unknown substance, will be added to the kitchen chemistry laboratories. Technologies designed to improve communication among students and between the students and the instructor, including a discussion board and chat room, are also being explored, as is the possibility of supplying a subset of students with computer-based data acquisition equipment to measure temperature, pressure, $\mathrm{pH}$, conductivity and light absorption.

The distance learning model described here also represents an excellent alternative to traditional methods for high school students in rural settings where advanced and AP chemistry courses are not offered. To 
test the feasibility of offering the course to this population, a pilot study was carried out. The highschoolers enrolled as special students at UNCW, and were entered into a special section of CHM 101 that was taught by the same instructor as the CFCC course. Because it was taken through UNCW, the course transferred as CHM 101 to any University in the country, ensuring the students four hours of college credit. An important additional benefit was the involvement of the high school science teachers, who work directly with the course instructors. Such collaborations break down barriers between the high schools and universities, and extend the benefits of university instruction to areas too isolated to participate in traditional ways. Variations of the kitchen laboratory experiments are also being designed to train middle and high school science teachers.

\section{ACKNOWLEDGMENTS}

The authors would like to acknowledge the following coworkers: Ms Jen Mullen, Current Kitchen Chemistry Instructor, Cape Fear Community College; Dr. Barbara Heath, Kitchen Chemistry Evaluator, University of North Carolina at Wilmington; Dr. Charles Ward, University of North Carolina at Wilmington; and Mrs. Ruby Casanova, Version I Instructor, Cape Fear Community College. Funding to develop the Kitchen Chemistry Experiments was provided through US Department Education FIPSE (LAAP) Grant: P339B990138.

\section{ABOUT THE AUTHORS}

Jimmy Reeves is associate professor of chemistry at the University of North Carolina at Wilmington and has researched the application of technology to chemistry instruction for the past thirteen years. He was the principle author of ActivChemistry, an interactive chemistry simulation published by Benjamin Cummings, and is co Principle Investigator of the Anytime, Anywhere Chemistry Experience and coauthor of Kitchen Chemistry, a set of general chemistry labs for distance learning students designed to be performed at home, soon to be published by Prentice Hall. He served four years on the ACS General Chemistry examination committee, and organized and presented over one hundred seminars at regional and national ACS meetings.

Doris Kimbrough is associate professor and chair of the department of chemistry at the University of Colorado at Denver. She is Project Director of the Anytime, Anywhere Chemistry Experience, a grant administered through the FIPSE program at the Federal Department of Education that produced the Kitchen Chemistry experiments described in above. Dr. Kimbrough is the coauthor of a commercial laboratory manual and numerous journal articles in chemical education. 